\title{
DO BIOPODER AO CUIDADO DE SI
}

\author{
FROM BIOPOWER TO THE CARE OF THE SELF
}

\section{Debora de Sa Ribeiro Aymore ${ }^{1}$ André Luiz Souza Coelho²}

\begin{abstract}
Resumo: Nosso artigo analisa a transição de ênfase de Michel Foucault da biopolítica, relacionada às populações, para o cuidado de si. O "biopoder" está relacionado, primeiramente, ao controle social exercido como um direito de morte do soberano sobre seus súditos e, a partir dos séculos XVIII e XIX, se operacionaliza por meio da administração dos corpos e na gestão da vida, em questões relativas à natalidade, à saúde pública e à migração. Torna-se um desiderato político-social a constituição dos corpos e mentes dóceis, aptas ao trabalho. No entanto, em suas obras tardias, nos últimos volumes da História da Sexualidade e suas aulas no Collège de France, entre 1980 e 1982, parte delas reunidas em $A$ bermenêutica do sujeito, Foucault transita para uma reelaboração da ética do cuidado, que se caracteriza pelo retorno à moral greco-romana para dela reelaborar uma ética como o modo como o indivíduo se constitui a si mesmo como um sujeito moral de suas próprias ações, isto é, a ética como a relação de si para consigo. A compreensão dos processos, a prática dos cuidados em torno de si, cria rupturas com os padrões que obscurecem a nossa consciência da natureza dos modos anteriores e interiores que sustentam e orientam as instâncias mais consolidadas e localizadas no centro de nossas vidas.
\end{abstract}

Palavras-chave: biopoder, Michel Foucault, cuidado de si.

\begin{abstract}
Our paper analyses the Michel Foucault's focus transition from biopolitics, related to population, to the care of the self. At first, "biopower" is related to social control exercised as life and death rights from the sovereign over its subjects and, in the $18^{\text {th }}$ and $19^{\text {th }}$ Centuries, reframed as bodies and life administration, in relation subjects such as birthrate, public health and immigration. Related to social and political goal centered on building docile bodies and minds, up to work. In Foucault's latter works, such as the last two volumes of History of Sexuality and his classes at Collège de France, from the 1980 e 1982, partially reunited on Hermeneutics of the Self, he turns to reprocessing the care of the self, characterized by the return to Greek and Roman morals, centered to reframe ethics as the means to individuals self-constitution as a moral agent responsible to its own actions, there is to say, an ethical proposal centered in one's self. A comprehension of such developments, the praxis of self-care, breaks certain patterns that obscure our knowledge on the nature previous and internal modes that sustained and guided more consolidated instances centered in our own lives.
\end{abstract}

Key-Words: bio-power, Michel Foucault, care of the self.

\footnotetext{
1 Professora substituta do Departamento de Filosofia da Universidade Federal do Paraná (UFPR), colaboradora e orientadora no Curso de Especialização em Estudos Culturais e Políticas Públicas (Poscult/UNIFAP). Membro da Associação Filosófica Scientiae Studia, pesquisadora do Núcleo de Estudos da Cultura Técnica e Científica (NECTeC/ UFPR), do Grupo de Pesquisa Ética e Política (UEAP) e do Estudos Interdisciplinares em Cultura e Políticas Públicas (UNIFAP). Orcid: http://orcid.org/0000-0003-1384-6681

2 Professor Adjunto IV de Teoria do Direito na Universidade Federal do Rio de Janeiro (UFRJ)
} 


\section{INTRODUÇÃO}

Há pelo menos duas interpretações possíveis sobre o biopoder. A primeira, que explora seus aspectos negativos, enfatizando a interferência externa de instituições políticas e sociais nos corpos e mentes dos indivíduos e das populações, que determinam seu desenvolvimento visando finalidades exteriores a si próprios. A segunda explora, ao contrário, seus aspectos positivos, ressaltando o quanto a participação em estratégias de biopoder tornaram homens e mulheres, seus corpos e suas mentes antes sujeitados, agora participantes esclarecidos das relações de poder e de resistência ao poder.

Assim, estudar as relações de poder requer não apenas apontar tensões e pontos de crítica lá onde o poder subjulga parcelas significativas da população. É ainda demonstrar o potencial de emancipação mesmo quando participamos de tais relações. A emancipação, no entanto, nunca será absoluta, uma vez que para Michel Foucault (1926 - 1984), há uma microfísica do poder cuja análise genealógica ${ }^{3}$ demonstra as suas microcapilaridades, fazendo com que mesmo na esfera privada onde, supostamente, o poder não se exerceria, ele está presente. É na família, na escola, e não apenas no Estado, que o poder se revela.

É uma densa trama de poderes que se dobram, se convertem, se alinham ou se isolam: uma dinâmica viva, transversa, que não pode ser engessada no formalismo e cuja lógica não é aquela dedutivo-sistemática, mas imanente, viva: uma rede microfísica onde as periferias não são menos importantes do que o centro, na qual as relações de força são disparidade concretas, situações de poder, localizadas e instáveis, de dissimetria. Esse é o traço gerador, dinâmico do poder: poder de vida e sobre a vida (BAZZICALUPO, 2017, p. 41).

Deste modo, nosso artigo perfaz um itinerário filosófico e histórico centrado em algumas obras de Foucault e comentadores, buscando, mais que a originalidade absoluta da descoberta teórica, um itinerário analítico capaz de exercer, no limite, certa aplicação para o conhecimento acadêmico, fornecendo bases tanto para a formulação de estudos posteriores, quanto para ações sociais menos subalternizadas, que possibilitem o exercício da resistência como consequência natural das relações sociais de poder.

\section{DO PODER DE MORTE AO PODER SOBRE A VIDA}

O poder exercido na modernidade supera, em parte, o modo de exercício do poder soberano, também conhecido por jurídico legal ou clássico (cf. TAYLOR, 2018, p. 58), na medida em que este exerce o poder de vida e de morte em relação aos súditos. No último capítulo de História da sexualidade: a vontade de saber (1976) está expressa a correlação entre a soberania e o exercício da autoridade do pai em relação aos filhos e aos escravos em Roma4. Mesmo o poder de vida e de morte exercido pelo soberano não é absoluto, uma vez que seu “[...] exercício está condicionado à defesa do soberano e à sua sobrevivência enquanto tal” (FOUCAULT, 1988,

\footnotetext{
${ }^{3}$ Nos escritos de 1961 a 1976, Foucault explora novos territórios utilizando-se tanto da arqueologia, influenciado por Immanuel Kant, quanto da genealogia, influência recebida de Friedrich Nietzsche, tornando a loucura (1961), o olhar médico e as ciências humanas (1966), bem como a prisão (1974) e a psicanálise (1976), novos terrenos para suas análises histórico-filosóficas. Enquanto na arqueologia, Foucault analisa a relação entre saber e poder, na genealogia ele explora a moral dos costumes e das instituições modernas (cf. BILLOUET, 2003, p. 16 - 17).

4 Trata-se da patria potestas (cf. FOUCAULT, 1988, p. 127).
} 
126 - 127). A disparidade com o período moderno torna-se aos poucos evidente, pois, na modernidade, destaca-se o poder de produção e de mobilização das forças, poder que gera a vida.

Do ponto de vista histórico, Foucault identifica duas formas modernas de exercício do poder e uma pré-moderna. O poder soberano é, justamente, esta forma pré-moderna, sendo sucedido pelo poder disciplinar ${ }^{5}$ e, finalmente, pelo biopoder ${ }^{6}$. Richard A. Lynch sugere um modelo piramidal para que compreendamos mais facilmente estas distintas formas de exercício do poder. No ápice da pirâmide estaria o poder soberano representado pelo rei, a seguir por seus ministros e, por fim, na base da pirâmide, os súditos (cf. LYNCH, 2018, p. 23). Segundo Foucault: "O poder era, antes de tudo, nesse tipo de sociedade, direito de apreensão das coisas, do tempo, dos corpos e, finamente, da vida; culminava com o privilégio de se apoderar da vida para suprimi-la" (FOUCAULT, 1988, 128).

Porém, a esta visão estanque, em que o poder emana de uma posição hierárquica superior e privilegiada, Foucault opõe uma imagem do poder que se realiza de modo mais complexo, inter-relacionado e dinâmico. Uma vez que o poder “[...] pode ser encontrado em todas as interações sociais" (LYNCH, 2018, p. 26). A partir dos anos de 1970, floresce a reflexão de Foucault sobre o poder, particularmente em suas obras Vigiar e punir de 1975, História da sexualidade: a vontade de saber de 1976, assim como nos cursos do Collège de France de 1974 e 1979.

Foucault, porém, resiste a chamar sua análise de teoria do poder, justamente por não querer passar a impressão de algo acabado, uma análise fechada. Reflete, assim, pressentindo a falibilidade de sua abordagem empírico-teórica. No entanto, insiste no caráter onipresente do poder, “[...], isto é, que o poder seja coextensivo com o campo das relações sociais; que o poder esteja entrelaçado com outros tipos de relações sociais e seja revelado nelas" (LYNCH, 2018, p. 26).

Há uma faceta jurídico-discursiva ${ }^{7}$ do poder, que apresenta cinco características: (1) ele opera por meio de interdições, (2) apresenta estrutura normativa, que cria dualismos (legal, ilegal; permitido, proibido). Assim, (3) realiza-se segundo a dinâmica de proibição e lei de interdição. (4) Suas leis revelam a lógica da censura, por criar o silenciamento e a negação de sua existência e, finalmente, (5) este poder é universal e uniforme (cf. LYNCH, 2018, p. 28).

Até o século XVII, período em que Thomas Hobbes (1588 - 1679) escreve suas obras, o poder soberano predomina. Considera-se que a lei não tem poder, adquirindo respeitabilidade quando a espada o garante. Tanto para Foucault, quanto para Hobbes, o poder soberano

\footnotetext{
${ }^{5}$ Em uma fórmula bastante sucinta, Hoffman afirma que: “[...] o poder disciplinar produz indivíduos como seus objetos, objetivos e instrumentos" (HOFFMAN, 2018, p. 42). Porém, além de o corpo ser também o alvo de seu exercício, separando-o e individualizando-o, a especificidade do poder disciplinar é o fato de ele estabelecer relação de controle, de tal modo a direcioná-lo para a utilidade e docilidade (cf. HOFFMAN, 2018, p. 43). Para tanto, há aplicação de técnicas: "a observação hierárquica, o julgamento normalizador e o exame" (HOFFMAN, 2018, p. 46).

${ }^{6}$ No entanto, Edgardo Castro aponta para quatro diferenças entre a disciplina e a biopolítica: "1) Quanto ao objeto: a disciplina tem como objetivo o corpo individual; a biopolítica, o corpo múltiplo, a população o homem como ser vivente, pertencente a uma espécie biológica. 2) Quanto aos fenômenos considerados: enquanto as disciplinas consideram os fenômenos individuais, a biopolítica estuda fenômenos de massa, em série, de longa duração. 3) Quanto aos seus mecanismos: os mecanismos das disciplinas são da ordem do adestramento do corpo (vigilância hierárquica, exames individuais, exercícios repetitivos); os da biopolítica são mecanismos de previsão, de estimativa estatística, medidas globais. 4) Quanto à finalidade: a disciplina se propõe obter corpos economicamente úteis e politicamente dóceis; a biopolítica persegue o equilíbrio da população, sua homeostase, sua regulação" (CASTRO, 2009, p. 60).

7 Jurídico exprime o aspecto normativo, o modelo de apresentação segundo o poder; discursiva por declarar proibições e tabus que interagem com o discurso e com as práticas cotidianas, difundindo a "lógica da censura" (cf. LYNCH, 2018, p. 29).
} 
representa este poder jurídico-discursivo (cf. TAYLOR, 2018, p. 60). O poder disciplinar, surgido a partir do século XVIII, torna aos poucos

[...] menos propensa a pôr fim à vida do criminoso e mais propensa a controlar a sua vida mediante táticas tais como a prisão, o tratamento psiquiátrico, a liberdade condicional e a liberdade vigiada (TAYLOR, 2018, p. 60).

Foucault demonstra que o poder funciona na ordem micro e na ordem macro e, embora tal característica seja uma consequência da onipresença do poder, este autor enfatiza sua análise em diferentes obras, respectivamente: a ordem micro em Vigiar e punir e a macro na História da sexualidade: a vontade de saber, e nos cursos do Collège de France (1974 e 1979).

Note-se, portanto, que ao invés de possuído, como seria esperado a partir de uma perspectiva de poder soberano, o poder é exercido e, diferentemente de sua forma pré-moderna, o poder se torna, na modernidade, uma prática dinâmica interna às próprias relações sociais. Por isso, não devemos compreendê-lo a partir dos seus lugares privilegiados (monarquia ou Estado), mas a partir da microfísica ${ }^{8}$. Esta característica interna remete às táticas e às estratégias ${ }^{9}$, que representam os cálculos, as metas e os objetivos a serem atingidos pelo exercício do poder (cf. LYNCH, 2018, p. 35).

No seu micronível, o biopoder ${ }^{10}$ é exercido sobre e pelos indivíduos, o que implica sua projeção e exercício sobre o corpo; mas, em seu macronível, projeta-se e é exercido sobre as populações, na chamada "biopolítica". A sexualidade é o terreno em que este poder é exercido. Desta maneira, a função biopolítica move-se

[...] nas instituições religiosas, nas formas pedagógicas, nas práticas médicas, nas estruturas familiares produz efeitos de subjetivação tanto nos indivíduos - obrigados a descobrir em si mesmos a força secreta da sexualidade - como nas populações em que o sexo e a sua gestão na reprodução funcionam como nexo entre indivíduo, espécie e macropolítica demográfica (BAZZICALUPO, 2017, p. 43).

O poder sobre a vida, no entanto, se constitui a partir do século XVII, primeiramente, na consideração do corpo como máquina, tornando possível associar valores de utilidade e docilidade. A esta anátomo-política aliou-se, por volta do século XVIII, o corpo-espécie, comprometido com índices de nascimento, envelhecimento e mortalidade, de saúde, o que requer o uso de controles e práticas reguladoras (cf. FOUCAULT, 1988, p. 131).

Em Apolítica de saúde no século XVIII, Foucault afirma que o cuidado médico com as doenças foi, até o final do século XVII, realizada por meio da assistência aos pobres, exceto em casos de epidemia, pois essas situações-limite que obrigavam, por vezes, a realização de quarentena

\footnotetext{
${ }^{8}$ João Paulo Ayub esclarece que: "Ao explicar a ascensão da burguesia na França, Foucault inverte a perspectiva de análise centrada na constituição e funcionamento do aparelho jurídico e na formação do Estado.De outro modo, ele aponta para o investimento cotidiano de 'mecanismos miúdos', 'microfísicos', num processo que, distante do brilho e da solenidade que marca a instituição dos direitos fundados em princípios igualitários, participa como sustentadora desses mesmos direitos" (AYUB, 2014, p. 22).

9 Para Foucault, as "táticas são as racionalidades locais de poder em casos particulares; estratégias, por outro lado, são os padrões de poder maiores, sistêmicos ou globais” (LYNCH, 2018, p. 39).

${ }^{10} \mathrm{Em}$ uma breve descrição, o biopoder se caracteriza como uma inversão do poder de causar a morte, pois: “Agora é sobre a vida e ao longo de todo o seu desenrolar que o poder estabelece seus pontos de fixação; a morte é o limite, o momento que lhe escapa; ela se torna o ponto mais secreto da existência, o mais "privado"' (FOUCAULT, 1988, p. 130).
} 
e o exercício de uma medicina mais autoritária (cf. FOUCAULT, 2011a, p. 359).

O mercantilismo, que se desenvolve desde o final do século XVI até o século XVII, se configurava como uma teoria econômica e uma prática política, intensificando a circulação das mercadorias mundialmente e incentivando a preocupação com a produtividade da população (cf. FOUCAULT, 2011b, p. 407). As práticas médicas, alinhadas às orientações econômicas ${ }^{11}$, políticas e ao desenvolvimento científico da época, emergem em diversos pontos da experiência social, tornando a Medicina e o cuidado com a saúde, gradualmente, uma questão coletiva. Assim, no final do século XVIII, foi possível testemunhar "[...] o planejamento da sociedade como meio ambiente de bem-estar físico, saúde ótima e longevidade” (FOUCAULT, 2011a, p. 361). A polícia exerce, então, estas funções vinculadas não apenas à saúde, mas igualmente à ordem e ao enriquecimento. Assim, a medicina passa a exercer um papel relevante na higiene e no controle social, pois

o desaparecimento das grandes tempestades epidêmicas, a baixa taxa de morbidade, o prolongamento da duração média de vida e a supressão de vida para cada idade. Essa higiene, como regime de saúde das populações, implica, por parte da medicina, certo número de intervenções autoritárias e de tomadas de controle, inicialmente em um espaço urbano geral, pois este constitui o meio próprio e mais perigoso para a população. A instalação dos diferentes bairros, sua umidade, sua exposição, o arejamento da cidade inteira, seu sistema de esgotos o escoamento das águas residuais, a instalação dos cemitérios e abatedouros, a densidade populacional, tudo isso constitui fatores de papel decisivo no que concerne à mortalidade e à morbidade dos habitantes. A cidade e suas principais variáveis especiais aparecem como um objeto a ser medicalizado (FOUCAULT, 2011a, p. 366 - 367).

Tal função higienista está, portanto, intimamente vinculada ao desenvolvimento econômico, sendo necessário manter e fomentar o estado de saúde. Exercido individual e coletivamente, o poder passa a direcionar o potencial produtivo e reprodutivo da vida. Assim, mesmo que não considerando o Estado como lugar ou fonte do poder (cf. CASTRO, 2014, p. 40 41), ele terá papel relevante nas relações de poder, operando conjuntamente com os indivíduos na população.

\section{BIOPODER, MEDICINA E OS CORPOS DÓCEIS}

Vários fenômenos podem ser elencados como exemplos do exercício da "biopolítica", que é a faceta política do biopoder, quando este exerce poder sobre a vida dos indivíduos e, em especial, das populações. Laura Bazzialupo (2017) aponta para alguns dos desdobramentos, tal como nos casos da medicalização do corpo, da gestão policiada das populações, bem como na distinção entre o que está ou não adaptado (fitness) e daqueles que podem ou são impedidos de permanecer em território estrangeiro no fluxo de imigrações (cf. BAZZICALUPO, 2017, p. 15 - 17).

Desta maneira, a gestão da vida (individual e das populações) aproveita-se do conhecimento

\footnotetext{
11 Segundo Foucault, o biopoder foi “[...] elemento indispensável ao desenvolvimento do capitalismo, que só pôde ser garantido à custa da inserção controlada dos corpos no aparelho de produção e por meio de um ajustamento dos fenômenos de população aos processos econômicos” (FOUCAULT, 1988, p. 132).
}

PRACS: Revista Eletrônica de Humanidades do Curso de Ciências Sociais da UNIFAP https://periodicos.unifap.br/index.php/pracs ISSN 1984-4352 Macapá, v. 12, n. 1, p. 09-22, jan./jun. 2019 
científico, e a política se alia a economia, estabelecendo distinções que não dizem respeito necessariamente aos corpos e às mentes, pois, neste sentido mais fundamental, encontraríamos certas semelhanças entre os seres humanos (necessidade de nutrição, mortalidade etc.) e não nossas distinções (normal ou anormal, adaptado ou não adaptado etc.). O conhecimento cria, então, camadas de justificação que naturalizam comportamentos sociais e que expressam, por vezes, a opressão, a submissão, a dor e o sofrimento físico e simbólico em nome da civilização e do progresso constantes. É por isso que a análise biopolítica

[...] ilumina criticamente o exercício de poder presente naqueles dispositivos morais e jurídicos que legitimam e organizam a ação normativa sobre a vida, discursos biojurídicos e bioéticos que se alicerçam na natureza do ser vivo para estruturar a intervenção política sobre o mesmo (BAZZICALUPO, 2017, p. 18).

A ênfase na vida modifica a política, compreendida em sua interação clássica e ruptura moderna. Em 1900, o termo "biopolítica" se refere aos desenvolvimentos do século anterior, especialmente ao projeto positivista de que o conhecimento científico que intercede em aspectos vitais. Destaca-se o projeto de melhoria da vida humana, fazendo com que "[...] a produtividade do poder em normalizar comportamentos desviantes quando segue aquelas que são reconhecidas como leis da natureza, as normas biológicas" (BAZZICALUPO, 2017, p. 22).

Ao lado da civilização, no entanto, caminha a barbárie. Pois, vinculado ao positivismo programático e direcionado à melhoria da vida humana, a própria biologia evolutiva é utilizada como base para eugenia e para distinções raciais próprias do início do século XX, tais projetos expressam a evidência de que a sobrevivência de alguns requer, inadvertidamente, o sacrifício daqueles não adaptados às normas biológicas ${ }^{12}$.

Foucault, no entanto, ao desenvolver sua análise na esteira do médico e filósofo Georges Canguilhem (1904 - 1995), requer a compreensão de um movimento que inicia no patológico e se encaminha para o normal, considerando o "normal" apenas uma forma de equilíbrio instável do organismo. Assim, a medicina, a sociologia, a economia, a psicologia social, a antropologia cultural são influenciados pela biologia evolucionista do século XIX (cf. BAZZICALUPO, 2017, p. 24 e 26).

Mesmo o saber, explicitado no discurso, expressa o poder e, no biopoder, o corpo é o objeto investigado e submetido, tornando "[...] ilusória a independência entre saber e poder" (BAZZICALUPO, 2017, p. 39). Permitindo-nos afirmar, então, que mesmo no conhecimento que se pretende objetivo, valores (individuais e sociais) intercedem ${ }^{13}$. Aliás, é justamente a associação saber-poder ${ }^{14}$, que torna seus mecanismos persuasivos e não repressivos, como no

\footnotetext{
12 Segundo Taylor, no século XIX, europeus e norte-americanos precisaram lidar com o aumento da população fruto da urbanização crescente. A criminalidade, a doença mental, o alcoolismo, a promiscuidade e a prostituição preocupavam a classe média, inclusive porque esta parcela privilegiada da população reproduzia-se mais lentamente. Há suspeita de que a raça (humana) pudesse estar entrando em estado de degenerescência. A resposta a tais preocupações foi fornecida pela engenia (eu, bom ou bem, e genes, nascer), termo cunhado pelo estatístico Francis Galton para a ciência que estuda os fatores que melhoram ou pioram a qualidade racial das próximas gerações. $\mathrm{O}$ ápice atingido na primeira metade do século XX disseminava o discurso evolucionista às sociedades humanas, ao ponto de que a proteção dos doentes, dos pobres e dos fracos fosse considerada um impedimento à condição natural de sobrevivência dos mais aptos (cf. TAYLOR, 2018, p. 71 - 72).

13 Para uma abordagem filosófica esclarecedora sobre a relação entre a ciência contemporânea e os valores recomendamse os trabalhos do filósofo australiano Hugh Lacey, tal como a obra Is science value free? Values and scientific understanding (1999).

${ }^{14}$ Segundo Hoffman, foi a generalização do poder disciplinar que permitiu o estreitamento gradual da relação entre saber
}

PRACS: Revista Eletrônica de Humanidades do Curso de Ciências Sociais da UNIFAP https://periodicos.unifap.br/index.php/pracs ISSN 1984-4352 Macapá, v. 12, n. 1, p. 09-22, jan./jun. 2019 
caso do poder disciplinar, e visa "[...] captar uma intrínseca produtividade de 'vida': a capacidade dos discursos de verdade de produzir vidas concretas, subjetivações” (BAZZICALUPO, 2017, p. 40).

Assim, na interface entre a produção de conhecimento e o exercício do poder, o discurso é o instrumento, o efeito, o obstáculo, o apoio e também a possibilidade de exercer a resistência. Associado ao discurso que produz poder, e é produzido pelo poder, emerge a possibilidade de emancipação, mesmo que parcial, momentaneamente e cujo equilíbrio seja instável. Afinal, o poder está no próprio sujeitado, pois “[...] o poder do dominado não é alheio à força de verdade positiva, dispositiva, que o orienta” (BAZZICALUPO, 2017, p. 47).

Tanto no dominador, quando no dominado, nas relações societárias macro e micro, dentro e fora dos indivíduos e das populações, o biopoder e sua contraparte biopolítica emergem na genealogia do poder de Foucault como causa e efeito da dinâmica da vida. Neste particular, a Medicina é considerada, primeiramente, a partir da arqueologia do olhar médico em $O$ nascimento da clínica (1963) e terá um papel relevante no desenvolver de suas obras. Assim, mesmo que desde a conversão do Imperador Constantino (em 323) a Igreja estivesse ocupada com a saúde das almas, passará a preocupar-se igualmente da saúde do corpo.

Eis o início do processo que levaria ao estabelecimento de uma sociedade sadia, que faz com que o médico ganhe um estatuto político. Enquanto no século XVII a medicina se ocupa da saúde, no século XIX ela gerencia a normalidade, tornando o conhecimento sobre o vivente seu tema central (cf. BILLOUET, 2003, p. 48). Porém, além das ciências da vida, as ciências do homem corroboraram para expansão deste processo. Aliás, estas ciências humanas manterão íntima inter-relação, uma vez que Foucault afirma que:

O homem das ciências humanas é este ser vivo que, de dentro da vida a que pertence inteiramente e pela qual é perpassado em todo o seu ser, constitui representações graças às quais vive, e a partir das quais detém essa estranha capacidade de poder se representar justamente a vida (FOUCAULT, 1988 apud BILLOUET, 2003, p. 487).

Quer como objeto das ciências da vida ou humanas, o corpo é, sem dúvida, central para a análise do poder. Este bios, a vida que se autoproduz e cria discursos para representação da própria vida, será perpassada por forças que direcionam sua potencialidade a criação de corpos úteis e de mentes dóceis. A Medicina do século XIX “[...] não pode ser dissociada da organização, nessa mesma época, de uma política da saúde e a consideração das doenças como problema político e econômico apresentado às coletividades, que devem tentar resolvê-los no nível de suas decisões de conjunto" (FOUCAULT, 2011a, p. 358).

No século XVIII, no entanto, é a saúde da população que se torna o objetivo principal, que havia passado, no século XVII, no contexto francês e na Europa, por uma questão de assistência aos menos afortunados, tornando fundamental a transformação dos pobres em mão de obra útil (cf. FOUCAULT, 2011a, p. 360). No século XVIII, a saúde se torna um imperativo que, ao mesmo tempo é “dever de cada um e objetivo geral” (FOUCAULT, 2011a, p. 361).

Justamente na interseção destes dois processos a medicina social se politiza e também se torna interesse da economia, as ciências do homem passam a contribuir em um contexto político e econômico de acumulação de homens:

e poder, de forma que no século XVIII já se encontram mutuamente implicados. Do ponto de vista arquitetônico, o Panóptico de Jeremy Bentham oferecerá o modelo para a expressão do poder disciplinar (cf. HOFFMAN, 2018, p. 50).

PRACS: Revista Eletrônica de Humanidades do Curso de Ciências Sociais da UNIFAP https://periodicos.unifap.br/index.php/pracs ISSN 1984-4352 Macapá, v. 12, n. 1, p. 09-22, jan./jun. 2019 
O grande crescimento demográfico do Ocidente europeu ao longo do século XVIII, a necessidade de coordená-lo e integrá-lo ao desenvolvimento do aparelho de produção, a urgência de controlá-lo por meio de mecanismos de poder mais adequados e mais concentrados fazem aparecer a "população", com suas variáveis em número, repartição espacial ou cronológica, longevidade e saúde, não só como problema teórico, mas como objeto da vigilância, análise, intervenções, operações modificadoras etc. (FOUCAULT, 2011a, p. 362).

Nota-se, portanto, que a vigilância não é suficiente, pois é necessário ainda que a mesma se converta em prática, em direcionamento ao objetivo visado, externo, portanto, à ação individual. Não se trata apenas de garantir o assujeitamento, mas de ampliar a utilidade. Neste sentido, a família torna-se agente da medicalização (cf. FOUCAULT, 2011a, p. 364), fazendo com que certas ações interventivas estejam presentes desde a gênese do indivíduo. No entanto, nos locais em que a intervenção médica não é adotada voluntariamente, as medidas de higiene são aplicadas de modo autoritário, pois nas

prisões, barcaças, instalações portuárias, hospitais gerais nos quais se encontram os vagabundos, mendigos, inválidos, os próprios hospitais cujo enquadramento médico era, na maior parte do tempo insuficiente, avivando e complicando as doenças de pacientes, quando difundindo germes patológicos no exterior (FOUCAULT, 2011a, p. 367).

A bio-história, portanto, objetiva e marca de modo intrínseco o corpo, embora não se realize apenas na particularidade da relação médico e paciente. Aliás, será a economia capitalista que fomentará a intervenção nos corpos, pois nesta o "[...] controle da sociedade sobre os indivíduos não se efetua mais apenas pela consciência ou pela ideologia, mas dentro e com o corpo. Para a sociedade capitalista, importava, antes de tudo, a biopolítica, o biológico, o somático, o corporal" (FOUCAULT, 2011b, p. 405). Assim, o desenvolvimento teórico e a aplicação prática da Medicina ${ }^{15}$ fazem parte da estratégia biopolítica.

Os questionamentos de Billouet instigam a pensar possíveis alternativas à sujeição passiva ao biopoder: "É o corpo inútil do hedonismo libertário uma alternativa ao corpo dócil da sociedade disciplinar? É preciso libertar o desejo contra a repressão religiosa e capitalista?” (BILLOUET, 2003, p. 153). Será justamente a partir do século XIX que uma nova tecnologia do sexo emergirá, não estando mais relacionada com a morte e com o castigo, mas com a vida e a doença (cf. BILLOUET, 2003, p. 155).

É possível notar, assim, a referida influência de Canguilhem na reflexão de Foucault, pois, em Vigiar e Punir (1975) e nas obras seguintes que se referem à biopolítica, decorrem "[...] diretamente da diferença do normal e do patológico como fundamento da medicina clínica, como modelo das ciências humanas e como ideia diretriz das normalizações disciplinares" (BILLOUET, 2003, p. 55 - 56).

É necessário igualmente que a liberdade seja considerada, uma vez que a resistência está intimamente vinculada ao exercício do poder. "Sem resistência, sem dois corpos (ou mentes)

\footnotetext{
${ }^{15}$ No mesmo texto $O$ nascimento da medicina social, Foucault detalha a história da medicalização na passagem da medicina do Estado, urbana e depois do trabalho desenvolvida, respectivamente, na Alemanha do começo século XVIII, na França do final do século XVIII e, finalmente, na Inglaterra (cf. FOUCAULT, 2011b). Porém, não sendo este o enfoque do presente artigo, nos ateremos apenas a destacar que é na medicina do trabalho em que a medicalização se dirige explicitamente aos pobres e trabalhadores (cf. FOUCAULT, 2011b, p. 419).
} 
empurrando ou puxando um contra o outro, não há relação de poder. E através da resistência as relações de poder podem ser sempre alteradas" (LYNCH, 2018, p. 38). Registram-se, deste modo, três características intrínsecas ao poder: sua onipresença, o fato de ele, especialmente a partir da modernidade, gerir a vida e, finalmente, a resistência como contraparte necessária do poder.

$\mathrm{Na}$ medida em que o poder disciplinar produz indivíduos ao dirigir-se aos corpos, ele os controla de modo meticuloso, exaustivo e contínuo. O interessante para os nossos propósitos está em que: com o aumento gradual da utilidade, ampliam-se também as aptidões e a capacidade de resistência dos indivíduos (cf. HOFFMAN, 2018, p. 42 - 43).

Mesmo Hobbes, no século XVII, seria resistente à intervenção na liberdade corporal, uma vez que, para ele, seria "[...] absurdo imaginar certos aspectos mundanos da vida, como a liberdade sobre o próprio corpo e a vida privada, sendo objeto de tais pactos [com o soberano]" (TAYLOR, 2018, p. 59, acréscimo nosso). O biopoder, ao contrário, incide no corpo e "[...] é internalizado por sujeitos em vez de exercido de cima mediante atos ou ameaças de violência, e porque está disperso por toda a sociedade em vez de localizado em um único indivíduo ou organismo do governo" (TAYLOR, 2018, p. 61).

Incidindo tanto individual, quanto coletivamente, o biopoder evolui a partir do poder disciplinar. Assim, a disciplina se torna uma "microtecnologia", enquanto a biopolítica uma "macrotecnologia", ambos incidindo sobre a vida (TAYLOR, 2018, p. 64). Julgando a partir da norma, prefigura-se a atitude coercitiva em relação ao anormal (cf. HOFFMAN, 2018, p. 47), mas será por intermédio das estatísticas e dos censos que o Estado moderno administrará a vida.

A demografia, as taxas de fertilidade, de natalidade, de imigração, de habitação, de mortalidade, a idade da população, são todos índices que impactam sobre a força de trabalho disponível (cf. TAYLOR, 2018, p. 64 - 65). A partir do século XVIII, inclusive os atos sexuais não reprodutivos ganham a atenção do Estado e, se para alguns, o desinteresse pela procriação é medicamente tratado, para outros, as ações políticas visam prevenir a possibilidade de procriação, tal como no caso das mulheres solteiras, dos pobres, dos criminosos e dos doentes ou deficientes mentais ou físicos (cf. TAYLOR, 2018, p. 66). Assim, segundo Foucault:

[...] a sexualidade se insere e adquire efeito, por seus efeitos procriadores, em processos biológicos amplos que concernem não mais ao corpo do indivíduo mas a esse elemento, a essa unidade múltipla constituída pela população. A sexualidade está na encruzilhada do corpo e da população. Portanto, ela depende da disciplina, mas depende também da regulamentação (FOUCAULT, 2010, p. 212).

Disciplina e regulamentação passam a fazer parte do exercício do biopoder, direcionado aos corpos ou às mentes. Os corpos dóceis são policiados ostensivamente e disciplinados; os indivíduos são mantidos isolados e, tendo suas forças direcionadas, perdem o ímpeto de resistência. Porém, no exercício do poder a resistência mantêm-se como contraparte indissolúvel. Requer-se, assim, a transição do homem sujeitado para o homem livre, capaz de resistir ao poder. Billouet caracteriza este horizonte de mudança ao afirmar que:

[...] o homem livre não é louco, nem doente, nem professor, nem médico etc. - mas meu irmão, teu irmão. Reconhecê-lo como irmão é, ao mesmo tempo, aceitá-lo em sua diferença sem hierarquizar as diferenças. O horizonte libertário de uma aceitação generosa das diferenças opõe-

PRACS: Revista Eletrônica de Humanidades do Curso de Ciências Sociais da UNIFAP https://periodicos.unifap.br/index.php/pracs ISSN 1984-4352 Macapá, v. 12, n. 1, p. 09-22, jan./jun. 2019 
se assim ao horizonte republicano de uma hierarquização baseada num critério que Foucault denunciará como normalização (BILLOUET, 2003, p. 42).

Deste modo, a diferença é reconhecida, mas não se torna motivo para a sujeição ou reificação do outro. No horizonte republicano resta a possibilidade de resistência ao poder quando este não apenas hierarquiza, mas, por intermédio do discurso, é aceito sem crítica. A análise do biopoder realizara por Foucault permanece necessária e atual. E, desse modo, o mesmo discurso que produz conhecimento e mentes dóceis pode, em igual proporção, apoiar a resistência quando necessário.

\section{O CUIDADO DE SI}

O tema do cuidado de si domina a parte final da obra e do pensamento de Foucault. Faz parte do assim chamado terceiro eixo de sua obra, o eixo da ética, tendo a arqueologia e a genealogia como seus antecessores.

Desde as obras e cursos sobre as várias formas de exercício do poder disciplinar, a internalização da fiscalização e do controle fora um componente central. Ficara claro que, em toda relação recíproca entre poder e subjetividade, está em jogo não apenas um enquadramento a partir de fora, das relações de poder em relação às dinâmicas do sujeito, mas também e principalmente um enquadramento a partir de dentro, uma prática ou técnica de si, como ele chamará mais tarde. Trata-se da "constituição dos modos de ser do sujeito por meio das diferentes práticas para relacionar-se consigo mesmo” (FOUCAULT, 2010, p. 5-7). Sem um engajamento ativo do sujeito em exercer sobre si mesmo controle segundo certo padrão específico, seria impossível que qualquer regime de poder, seja ele soberano, disciplinar ou biopolítico, obtivesse êxito.

É a explicitação desta descoberta, com seu ganho crescente de relevância explicativa, que mudará o foco dos interesses de Foucault para o tema da ética. Mais especificamente, para a história das relações dos sujeitos consigo próprios, a história das várias técnicas e práticas de controle de si que se sucederam no Ocidente, ou, de modo mais direto, a história do cuidado de si. Só esta história teria o duplo potencial de fornecer a explicação complementar necessária aos vários regimes de poder que a investigação genealógica trouxera à tona e proporcionar um vislumbre de técnicas e práticas de si que, em diferentes momentos históricos, representaram uma alternativa ao eixo no qual o poder pastoral se converteu em disciplina e biopoder. Se alguma alternativa ou resistência ao poder se oferece, esta não se encontra na utopia de uma sociedade desprovida de poder, mas está, ao contrário, na constatação histórica de que, em algum momento no tempo, formas mais livres de poder sobre si foram possíveis.

O período histórico que atrai em particular o interesse de Foucault, tornando-se o tema privilegiado do segundo volume de sua História da Sexualidade, intitulado O Uso dos Prazeres, é a Antiguidade tardia, pois, com a decadência da pólis e a substituição do ideal gregário do bom cidadão pelo ideal mais individual do sábio, ali se acumulam obras e discursos que visam guiar a vida prática em pelo menos quatro domínios: a dietética, que concerne a relação de cada indivíduo com o próprio corpo; a econômica, tocante ao governo da casa e da esposa; a erótica, que se preocupava com a relação com os mancebos; e ainda um quarto domínio, sem nome particular, que estabelecia uma relação entre a austeridade sexual e o acesso à verdade (cf. CASTRO, 2018, p. 141). Estes regimes de relacionamento consigo mesmo em cada um 
destes domínios foram as técnicas de si que, mais tarde, seriam apropriadas pelo cristianismo na forma de práticas monásticas e convertidas na base de referência para o exercício do poder pastoral.

Quando Foucault fala de técnicas de si, ele não se refere apenas a certa atividade ou disciplina que é praticada com regularidade. Na verdade, seguindo a metodologia que ele mesmo informa, é preciso enxergar cada uma das técnicas de si como um complexo histórico formado de vários elementos, cada um dos quais relevante naquilo que traz à tona sobre as estratégias e preocupações de cada período investigado. Este complexo é formado por: a substância ética, que é a parte ou aspecto do indivíduo que este põe em jogo em relação com a moral (por exemplo, sua alimentação, sua vida sexual etc.); o modo de sujeição, que é a maneira particular (por exemplo, via crença religiosa ou via tradição cultural) com que o indivíduo se reconhece vinculado com certa moral; a forma de trabalho ético, que é o tipo e regime de controle a que o indivíduo submeterá a substância ética em questão (certa dieta, certo tipo de austeridade etc.); e, finalmente, a teleologia ética, isto é, a finalidade ou conjunto de finalidades que se persegue por meio das práticas éticas em questão (por exemplo, o autodomínio ou a vida eterna) (cf. FOUCAULT, 1998, p. 26-29). Desta forma, a relação entre várias técnicas de si pode ser trazida à tona, formando um complexo ético mais rico e informativo.

Também é preciso deixar claro que Foucault não considera que a Antiguidade tardia foi algum tipo de paraíso da subjetividade desregulada ou, se não, regulada por preceitos completamente diferentes daqueles que mais tarde a moral cristã viria tornar dominantes por meio do poder pastoral. Pelo contrário, as hipóteses tomadas por ele são de que, por um lado, mesmo na transição da Antiguidade pagã para a Era cristã, os preceitos de vida ética recomendados com mais frequência no Ocidente se mantiveram mais ou menos os mesmos, inclusive o controle e frugalidade dos apetites, a suspeita e austeridade em relação à vida sexual e a condenação geral da homossexualidade; e, por outro lado, além disso, as práticas monásticas das ordens cristãs e as práticas aplicadas com mais frequência pelo dispositivo do poder pastoral nada mais foram que novas versões ou apropriações das técnicas de si que a Antiguidade tardia, via platonismo, neoplatonismo, epicurismo e estoicismo principalmente, legou ao cristianismo. A própria técnica da confissão, que se tornará central no poder pastoral, pode ser vista como exteriorização ritualizada e submetida ao escrutínio do outro (servindo como dispositivo de controle que cria a subjetividade típica do Ocidente) da mesma rotina de autoexame periódico de si mesmo, adotando a atitude crítica de um terceiro, recomendada nos guias espirituais por excelência da última Antiguidade, como Sêneca, Marco Aurélio, Plutarco, Epíteto e Agostinho (cf. CASTRO, 2018, p. 141-142).

As técnicas de si da Antiguidade tardia e da Era cristã partilham ainda de outro importante elemento em comum, que é a ideia de uma transformação ou conversão, identificada no período antigo com a epistrophe e, no cristão, com a metanoia. No platonismo e no neoplatonismo, a epistrophe requeria dar-se conta da própria ignorância, libertar-se das aparências e ilusões dos sentidos, reeducar-se para conceber a realidade em termos de ideias e preparar-se para o tipo de ascese ao mundo das formas perfeitas que apenas um longo exercício da dialética era capaz de proporcionar. Já a epistrophe do estoicismo se concentrava na distinção entre o que não depende de nós (a fortuna, a fama, o êxito e mesmo as consequências de nossas ações), que por isso não merece atenção nem esforço, e o que de fato depende de nós (a virtude, a escolha entre o bem e o mal, a pureza de intenção), que deve ser o foco de toda preocupação ética. Em ambos os casos, a epistrophe não era uma transformação brusca, e sim um longo processo 
de reeducação e um constante regime de autocontrole, para nos equiparmos com os meios de viver a vida digna do sábio. Já a metanoia cristã é outro tipo de conversão, na qual a transformação ou passagem é brusca e extrema, uma espécie de salto das trevas para a luz, da descrença para a fé, da fraqueza para a graça, do pecado para a salvação etc., a partir do momento em que se aceita a mensagem da revelação, a guia do pastor maior (o Cristo) e do pastor menor (o sacerdote), a purificação por meio dos sacramentos e da confissão e o compromisso com a renovação cíclica e perpétua desta transformação radical, para que não se desfaça no tempo nem na memória. Em vez de uma lenta caminhada rumo ao objetivo desafiador, como a epistrophe, a metanoia é uma súbita elevação à nova condição, cuja dificuldade prática não é (quando auxiliada pela Graça) da ordem do alcance, mas da conservação (cf. CASTRO, 2018, p.139).

A partir disso se pode perceber mais claramente qual o potencial, explicativo e crítico, do tema do cuidado de si. Se as formas de controle pelas quais o poder pastoral pôde se converter em disciplina e biopoder foram inspiradas, originalmente, pelas técnicas de si que a Antiguidade tardia deixou registradas em obras e discursos sobre a vida ética, então, o que houve em primeiro lugar na formação dos dispositivos de controle foi uma apropriação de métodos e processos de autoformação da subjetividade, com vista seja ao autodomínio, seja à salvação, na forma de métodos e processos de formação de uma subjetividade não apenas dócil e produtiva, mas também ajustada a dispositivos fora de seu controle e dependente deles para proteção e manutenção de sua identidade ao longo do tempo. Nisso também reside o potencial subversivo do cuidado de si, isto é, em reinstaurar no sujeito a sede de controle de sua própria subjetivação.

\section{CONCLUSÃO}

A partir do itinerário analítico realizado a partir da leitura das obras de Foucault e comentadores é possível observar como, a partir de uma concepção heterônoma da relação dos seres humanos com o poder, emerge gradualmente a concepção autônoma. Isto, no entanto, decorre de suas investigações históricas que, como frisado pelo próprio autor, são passíveis de revisão e novas formulações.

Assim, enquanto as práticas da sociedade disciplinar reiteram a vigilância minuciosa e constante, bem como o controle exercido sobre os corpos, submergidos em múltiplas camadas de força com os quais interagem tendo por fim estabelecer mentes e corpos dóceis, ou ainda adaptados segundo padrões de normalidade técnica e cognitivamente constituídos por saberes, a partir do exercício do biopoder a população torna-se objeto, na medida em que a capacidade de constituição da verdade se alia à produtividade, permitindo que os sujeitos vivam, embora sujeitados.

O cuidado de si enfatiza, portanto, a possibilidade não exatamente de escapar às relações de poder, que as leituras mais sombrias de Foucault apresentariam como uma impossibilidade teórica e prática, mas antes como uma coparticipação ativa nestas mesmas relações, de tal modo que os sujeitos, antes sujeitados, retomem aquela dimensão que subjaz aos mais evidentes modos de exercício do poder nas diversas interações em sociedade, que é a capacidade de opor resistência, mesmo que limitada, instável e circunstancial. Por diferentes vias o indivíduo percebe-se, portanto, como passivo e ativo na constituição de sua própria subjetividade, seguindo a dinâmica própria da biografia individual e da história coletiva.

O autor, Dr. André Coelho, agradece ao Colegiado de Filosofia da Universidade do 
Estado do Amapá (UEAP), nas pessoas dos professores Dilnéia Rochana Tavares do Couto e Rafael e Silva Lima, e pelo convite para ministrar o minicurso "Poder em Michel Foucault: poder pastoral, soberano, disciplinar e biopoder", ministrado nos dias 28 e 29 de novembro de 2019 ao longo da IV Semana Amapaense de Filosofia - Biopoder, financiado pela UEAP. Os estudos para preparação do minicurso, bem como os debates suscitados, contribuíram decisivamente para as conclusões registradas neste artigo.

A autora, Dra. Débora Aymoré, agradece ao Colegiado de Filosofia da Universidade do Estado do Amapá (UEAP) pela oportunidade de coordenar o projeto da publicação do dossiê Biopoder da Revista PRACS/ UNIFAP, bem como por fomentar e sediar a IV Semana Amapaense de Filosofia - Biopoder, com o apoio institucional e trabalho em equipe de alunos, professores, técnicos e demais colaboradores. À Universidade de São Paulo, na pessoa do supervisor de pós-doutorado, o Prof. Dr. Pablo Rubén Mariconda, considerando que a coordenação do dossiê Biopoder, da IV Semana Amapaense de Filosofia - Biopoder, assim como seus trabalhos acadêmicos publicados resultam também da realização do estágio pós-doutoral (2017 - 2018) no Departamento de Filosofia da USP.

\section{REFERÊNCIAS}

AYUB, João Paulo. Introdução à analítica do poder de Michel Foucault. São Paulo: Intermeios, 2014.

BAZZICALUPO, Laura. Biopolítica: um mapa conceitual. Tradução Luisa Rabolini. São Leopoldo, RS: Editora UNISINOS, 2017.

BILLOUET, Pierre. Foucault. Tradução Beatriz Sidou. São Paulo: Estação Liberdade, 2003 (Figuras do saber).

CASTRO, Edgardo. Vocabulário de Foucault: um percurso pelos seus temas, conceitos e autores. Tradução Ingrid Müller Xavier. Belo Horizonte: Autêntica Editora, 2009.

Introdução a Foucault. Trad. Beatriz de Almeida Magalhães. 1 ed. 3 reimpres. Belo Horizonte: Autêntica Editora, 2018.

FOUCAULT, Michel. História da sexualidade I: a vontade de saber. Tradução Maria Thereza da Costa Albuquerque e J. A. Guilhon Albuquerque. 13 ed. Rio de Janeiro: Edições Graal,1988.

. História da sexualidade II: O uso dos prazeres. Trad. Maria Thereza da Costa Albuquerque. 8a ed. Rio de Janeiro: Edições Graal, 1998.

. Em defesa da sociedade: curso no Collège de France (1975 - 1976). Tradução Maria Ermantina Galvão. 2 ed. São Paulo: Editora WMF Martins Fontes, 2010 (Coleção obras de Michel Foucault).

Ditos \& Escritos VII: arte, epistemologia, filosofia e história da medicina. Tradução Vera Lucia Avellar Ribeiro. Rio de Janeiro: Forense universitária, 2011.

A política da saúde no século XVIII. In: . Ditos \& Escritos VII: arte, epistemologia, filosofia e história da medicina. Tradução Vera Lucia Avellar Ribeiro. Rio de Janeiro: Forense universitária, 2011a [1976]. p. 357 - 373. tes, 2010.

O governo de si e dos outros. Tradução Eduardo Brandão. São Paulo: Martins Fon-

. O nascimento da medicina social. In:

. Ditos \& Escritos VII: arte, epistemo-

logia, filosofia e história da medicina. Tradução Vera Lucia Avellar Ribeiro. Rio de Janeiro: 
Forense universitária, 2011b [1977]. p. 402 - 424.

HOFFMAN, Marcelo. O poder disciplinar. In: TAYLOR, Dianna (Ed.). Michel Foucault: conceitos fundamentais. Tradução Fábio Creder. Petrópolis, RJ: Vozes, 2018, p. 41 - 57. LACEY, Hugh. Is science value free? Values and scientific understanding. London: Routledge, 1999.

LYNCH, Richard A. A teoria do poder em Foucault. In: TAYLOR, Dianna (Ed.). Michel Foucault: conceitos fundamentais. Tradução Fábio Creder. Petrópolis, RJ: Vozes, 2018, p. $23-40$.

TAYLOR, Dianna (Ed.). Michel Foucault: conceitos fundamentais. Tradução Fábio Creder. Petrópolis, RJ: Vozes, 2018. 